OPEN ACCESS

Edited by:

Sean Smith,

University of Michigan, United States

Reviewed by:

Dupoiron Denis,

Institut de Cancérologie de l'Ouest

(ICO), France

Erich Richter,

Central Michigan University,

United States

*Correspondence:

Terrence M. Pugh

terrence.pugh@atriumhealth.org

Specialty section:

This article was submitted to

Cancer Pain,

a section of the journal

Frontiers in Pain Research

Received: 30 March 2021

Accepted: 24 August 2021

Published: 01 November 2021

Citation:

Pugh TM, Squarize F and Kiser AL (2021) A Comprehensive Strategy to

Pain Management for Cancer Patients in an Inpatient Rehabilitation Facility.

Front. Pain Res. 2:688511.

doi: 10.3389/fpain.2021.688511

\section{A Comprehensive Strategy to Pain Management for Cancer Patients in an Inpatient Rehabilitation Facility}

\author{
Terrence M. Pugh ${ }^{1,2,3 *}$, Fabiana Squarize ${ }^{4}$ and Allison L. Kiser ${ }^{5}$ \\ ${ }^{1}$ Inpatient Oncology Rehabilitation, Atrium Health Carolinas Rehabilitation, Charlotte, NC, United States, ${ }^{2}$ Cancer \\ Rehabilitation, Levine Cancer Institute, Charlotte, NC, United States, ${ }^{3}$ Atrium Health, Charlotte, NC, United States, \\ ${ }^{4}$ Oncology Clinical Specialist, Atrium Health Carolinas Rehabilitation, Charlotte, NC, United States, ${ }^{5}$ Oncology Occupational \\ Therapist, Atrium Health Carolinas Rehabilitation, Charlotte, NC, United States
}

Cancer pain has been shown to have a significant negative impact on health-related quality of life (HRQoL) for people experiencing it. This is also true for patients admitted to inpatient rehabilitation facilities (IRFs). An interdisciplinary approach is often needed to fully address a person's pain to help them attain maximum functional independence and to ensure a safe discharge home. Improving a patient's performance status in an IRF may also be a crucial determinant in their ability to continue receiving treatment for their cancer. However, if a person is determined to no longer be a candidate for aggressive, disease modulating treatment, IRFs can also be utilized to help patients and family's transition to comfort directed care with palliative or hospice services. This article will discuss the interventions of the multidisciplinary inpatient rehabilitation team to address a person's pain.

Keywords: cancer, pain, inpatient rehabilitation facility, performance status, quality of life

\section{INTRODUCTION}

There were over 1.8 million new cancer diagnoses in the United States (US) in 2020 (1) and as of January 2019, there were 16.9 million cancer survivors in the US with that number anticipated to grow to 22.2 million by the year 2030 (2). With the growing number of people alive with a cancer diagnosis, rehabilitation services are often utilized to address treatment-related or diagnosis specific impairments for patients across the post-acute care spectrum (Figure 1). The majority of cancer rehabilitation services are delivered in outpatient settings with only $2.4 \%$ of patients receiving inpatient rehabilitation services (3). Despite the relatively small number of patients accessing inpatient services, improvement in health-related quality of life (HRQoL) has been well-established when the rehabilitation team addresses impairments such as pain, fatigue, anxiety/depression and physical functioning (4). The following will provide an overview of the interventions that may be utilized in inpatient rehabilitation facilities to address and treat pain in the oncology patient. This framework can be tailored in a person-centered manner with considerations for medical diagnoses, patient perceptions and preferences in regard to the interventions listed.

\section{MEDICAL INTERVENTIONS}

Identification of the type of pain experienced by the person is the first step in determining the appropriate intervention. There are several theories about the etiology of pain. Chronic pain (including cancer), inflammatory and neuropathic pain is a manifestation of neural plasticity in 


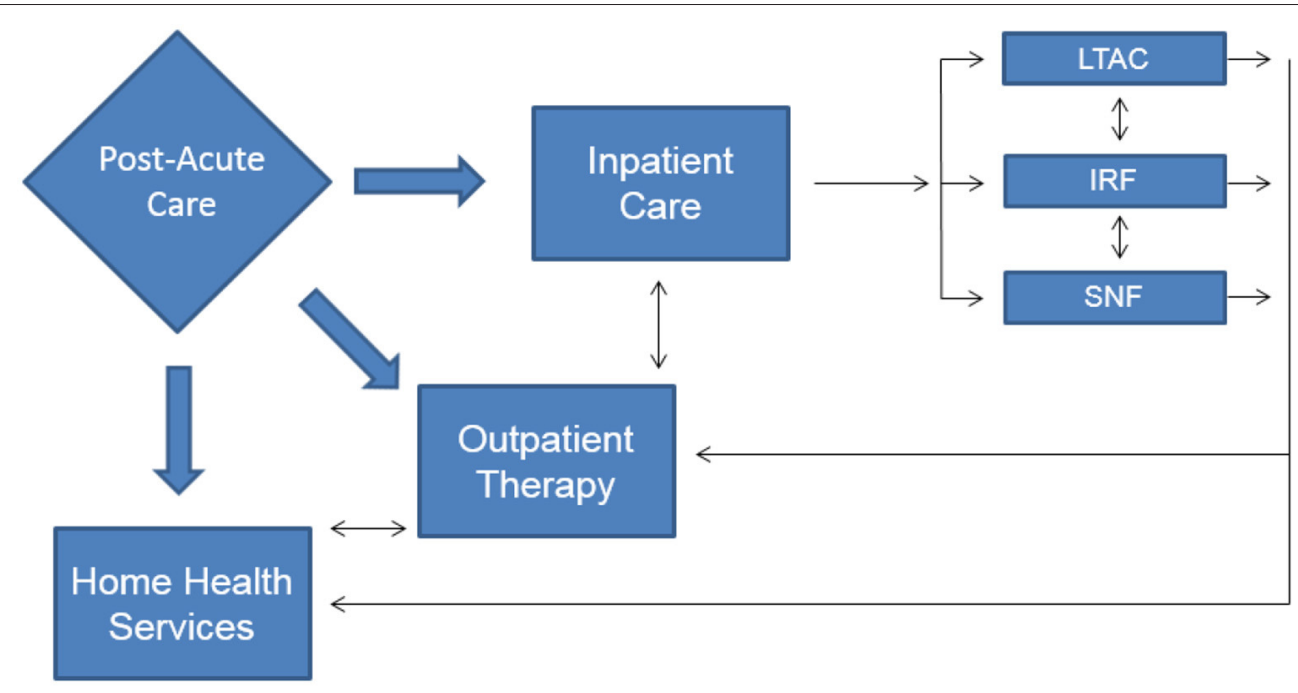

FIGURE 1 | Post-acute care rehabilitation options.

the peripheral (PNS) and central nervous system (CNS). This eventually leads to sensitization in both areas (5). Sensitization occurs due to chronic, hyperexcitability of sensory neurons in the PNS and an increase in the excitatory synapse transmission in the spinal cord, brain stem and cerebral cortex (5). Sensitization in the CNS has been shown to lead to long-term potentiation of pain in animal studies and is also a proposed mechanism in humans.

Fifty-six percentage of adults with cancer experience moderate to severe pain monthly (6) with $53 \%$ of people at all stages of cancer have pain (7). Pain can be further divided into more specific categories including acute (vs. chronic) pain, nociceptive (vs. neuropathic), migrainoid, post-operative, musculoskeletal/myofascial, osteoarthritic or cancer-related pain (8). Comprehensive pain management includes, pharmacologic, non-pharmacologic, integrative and interventional strategies (9). Clinicians should consider allergies, indications and contraindications for the recommended therapies prior to implementing a treatment plan.

\section{Opioids}

Cancer that is localized or metastasized is often very painful. The World Health Organization (WHO) pain ladder was originally designed in 1986 for patients experiencing cancer-related pain (10). The original ladder had three rungs (Figure 2). Early observational studies showed that when using this approach, $73 \%$ of people with cancer-related pain could achieve control (11). More recent data shows that strong opioids achieve a $75 \%$ response rate in reducing pain intensity by 3 points using a $0-10$ scale (12). The goal of utilizing opioids in cancer pain management is to achieve adequate analgesia to improve function while minimizing adverse effects. In addition to the risk for addiction seen in other non-malignant, chronic pain patients, oncologic patients may also experience constipation, cognitive "clouding," heartburn, nausea, hypogonadism, fatigue, infertility, osteoporosis/osteopenia, reduced libido, reduced frequency/duration or absence of menses, neurotoxicity, myoclonus, mood effects, increased risk for falls and new onset or worsening obstructive sleep apnea among others (13). To minimize the risks associated with chronic or high morphine milligram equivalent (MME) dosing, prescribers can use opioid conversion charts when switching between opioids (14). Risk of adverse events can also be mitigated by careful history taking and identification of risk factors including previous substance abuse or smoking. Pain agreements, pill counts, random drug testing and reviewing data from prescription drug monitoring programs can also be utilized to decrease the likelihood of misuse (13). Patient education about drug storage and disposal have also been shown to increase rates of safe opioid utilization (15).

\section{NSAIDs and Acetaminophen}

For peri-operative pain a multi-modal approach including NSAIDs and acetaminophen has been recommended (8). For post-operative pain, NSAIDs (including cyclooxygenase2 [COX-2] inhibitors) have also been shown to be effective. Celecoxib, a COX-2 inhibitor, dosed at 200 and $400 \mathrm{mg}$ showed a 33 and $44 \%$ pain reduction, respectively, compared to placebo (16). Although there was concern about increased cardiac morbidity and mortality with utilization of celecoxib, a 2016 study showed non-inferiority of celecoxib to ibuprofen and naproxen in regard to cardiovascular safety for the treatment of arthritic pain (17). A single dose of ibuprofen was also shown to achieve $50 \%$ pain relief in half of patients with moderate to severe post-operative pain (18).

Acetaminophen is an option for mild to moderate pain and for fever reduction. At lower doses it is generally well-tolerated but does have hepatoxic potential and can even cause serum transaminase elevation (19). Close monitoring of liver function is recommended while on acetaminophen containing compounds. Patients taking acetaminophen should limit intake to $<4,000 \mathrm{mg}$ in a 24 -h period. 


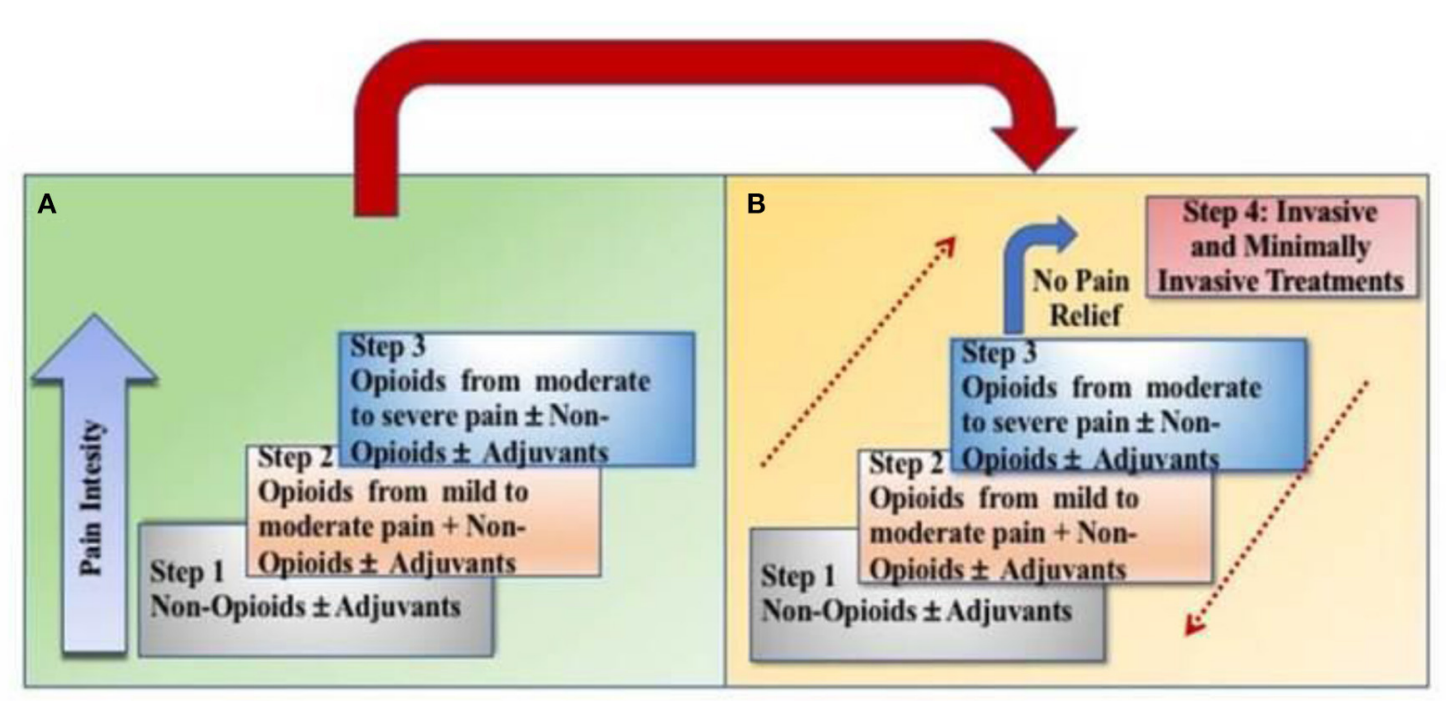

FIGURE 2 | Transition from the original WHO three-step analgesic ladder (A) to the revised WHO fourth-step form (B). The additional step 4 is an "interventional" step and includes invasive and minimally invasive techniques. This updated WHO ladder provides a bidirectional approach.

\section{Neuropathic Pain}

Chemotherapy-induced peripheral neuropathy (CIPN) is a clinical condition caused by neurotoxic medications used in the treatment of oncologic diagnoses. Common offending agents are taxanes, platinum-based compounds, vinca alkaloids, epothilones, eribulin, and bortezomib (20). CIPN not only impacts the nerves of the extremities causing pain, but also can cause throat discomfort, odynophagia and muscle cramps (19). Several classes of medications, included as adjuvants according to the WHO analgesic ladder, can be used to treat neuropathic pain. Tricyclic antidepressants (TCAs), serotonin norepinephrine reuptake inhibitors (SNRIs), anticonvulsants, topical analgesics, corticosteroids, bisphosphonates and cannabinoids have been used to treat painful neuropathy (21) (Table 1). Although a recent analysis showed that preventive medications, including acetyl-L-carnitine, should not be used to prevent CIPN. Treating oncologists can consider dose-reduced or alternative oncologic therapy. If a person develops painful neuropathy due to chemotherapy, then duloxetine should be offered (20). Topical treatment, dissolvable mucosal medications and injectable botulinum toxin have also been used to treat neuropathic pain. A 2015 review showed that topical lidocaine patches were safe and tolerable in people with neuropathic pain (22), however these studies showed efficacy that lasted $<3$ weeks duration (23). Topical capsaicin (patches or cream) may be effective in painful neuropathy with botulinum toxin type A also showing efficacy in peripheral neuropathic pain (22).

\section{Interventional Therapy}

Recently a fourth rung was added to the WHO analgesic ladder and a bi-directional approach was added to include non-pharmacologic treatments for pain management including acute and chronic cancer pain. This allows for escalation and de-escalation of the pain management strategy as the person's
TABLE 1 | Examples of neuropathic pain agents.

\begin{tabular}{|c|c|}
\hline Class & Medication examples \\
\hline Tricyclic antidepressants (TCAs) & $\begin{array}{l}\text { Amitriptyline (Elavil@), Nortriptyline } \\
\text { (Pamelor®) }\end{array}$ \\
\hline $\begin{array}{l}\text { Serotonin norepinephrine reuptake } \\
\text { inhibitors (SNRIs) }\end{array}$ & $\begin{array}{l}\text { Duloxetine (Cymbalta®), Venlafaxine } \\
\text { (Effexor®) }\end{array}$ \\
\hline Anticonvulsants & $\begin{array}{l}\text { Gabapentin (Neurontin } ®) \text {, Pregabalin } \\
(\text { Lyrica®) }\end{array}$ \\
\hline Topicals & $\begin{array}{l}\text { Capsaicin, Lidocaine (cream, } \\
\text { Lidoderm® patch) }\end{array}$ \\
\hline
\end{tabular}

clinical condition dictates. These include, but are not limited to, interventional procedures such as epidural or intrathecal analgesia, neuromodulation with or without a pump, nerve blocks or ablation procedures (23). Although these procedures may be beneficial for patients, interventional pain management is not often done in inpatient rehabilitation settings due to the need for prior authorization (PAs) and reimbursement limitations $(24,25)$. These should be considered in an outpatient setting if clinically indicated.

\section{Complementary Therapy}

Acupuncture can be considered for patients with acute and chronic pain including cancer pain. This intervention is effective because sometimes cancer-related pain is difficult to classify as it is non-nociceptive and non-neuropathic (26). In certain animal models, electroacupuncture can release endogenous opioids from lymphocytes, monocytes, macrophages and granulocytes. This stimulation, in turn, suppresses pain signals in peripheral nerves (27). Electroacupuncture was shown to be effective in rats with both bone cancer and prostate cancer. This intervention was 
shown to decrease dynorphin and IL-1 $\beta$ to achieve analgesia (26). Inhibition of subfamily $\mathrm{V}$ member 1 protein through electroacupuncture was helpful in pain regulation in mice with carcinoma (28). In spite of these promising results, the use of acupuncture cannot be definitively recommended for the prevention of nor treatment of CIPN following the administration of neurotoxic chemotherapy (20). However, acupuncture and acupressure have been shown to be effective in reducing non-neuropathic cancer related pain and decreased use of analgesics (29).

Massage therapy has been shown to reduce cancer pain by $\sim 40 \%$ (30). A recent meta-analysis showed that massage, including body massage, foot reflexology and aroma massage, was effective for cancer pain related to surgery, chemotherapy and metastatic disease. These effects were noted in all cancer types including breast and gastrointestinal malignancies (31). However, the effectiveness of massage therapy in managing cancer pain may also be influenced by other factors including the environment, music and aromas present during the session (32). Both acupuncture and massage therapy can be considered as adjunctive therapy if a qualified and licensed practitioner is available within the IRF.

\section{THERAPY INTERVENTIONS}

In spite of aggressive medical management there are times that people with cancer pain require additional interventions to achieve pain control. A multidisciplinary team approach is utilized in inpatient rehabilitation facilities to address impairments, including pain, related to a patient's diagnosis and/or treatment. In addition to medical interventions, physical and occupational therapists along with rehabilitation nurses can assist people with cancer in managing their pain.

\section{Transcutaneous Electrical Nerve Stimulation}

Transcutaneous electrical nerve stimulation (TENS) is a noninvasive modality that has been indicated to help with a variety of pain complaints, but most effective in neuropathic pain. The two most common types of TENS therapy are high frequency, low intensity TENS and acupuncture-like TENS (33). TENS works by utilizing the "gate theory" in which cells in the dorsal horn of the spinal cord are over stimulated thereby blocking pain signals to mitigate pain sensation (34). Although it may be beneficial for certain types of non-malignant pain, the data is inconclusive if it is beneficial for cancer-related pain (35). This should still be considered in patients with other non-malignant pain complaints. If TENS is utilized in a patient with an oncologic diagnosis, considerations must be made for contraindications including in areas overlying active tumor or in a person with unmanaged disease (36).

\section{Manual Therapy}

Manual therapy (MT) is a complementary technique that uses precise hand techniques to improve muscular tissue restriction/mobilize soft tissue, relieve pain and to promote psychological well-being. Manual therapy can be performed by massage therapists, osteopathic medicine practitioners, chiropractors and physical therapists (37). Many people with cancer have utilized manual therapy to help with pain relief and to help improve well-being (38). A recent review showed that manual therapy was effective in managing cancerrelated pain and improved overall feeling of wellness. More research is needed to determine if manual therapy can help with fatigue, anxiety, depression or nausea (36). Practitioners should use caution in insensate areas or in areas of vascular compromise. MT should be avoided in areas impacted by radiation dermatitis or over fragile bony areas due to metastatic disease or osteoporosis (35). Patients with myofascial pain syndrome are at risk of developing myofascial trigger points. In patients with pancreatic cancer, dry needling has been shown as an effective adjunct to neurolytic blocks for treatment of pain (39).

\section{Mindfulness Exercises}

Mindfulness-based interventions have been used in the oncology population to reduce psychological distress. These interventions help reduce anxiety and depression, however improvement in other oncology specific impairments, including pain, have not been as well-studied (40). Cillessen et al. did show that mindfulness-based interventions did show improvement of oncologic impairments including fear of cancer recurrence, fatigue, sleep disturbance and pain (40). Mind-body exercise have been shown to positively impact bodily functions and improve pain by combining exercise with mental focus (41). Pilates have been shown to be effective in managing pain in patients with breast cancer (42). Yoga courses have also been utilized in the cancer rehabilitation population. Although yoga was shown to improve QoL, stress and fatigue in a recent analysis, improvement in pain was not shown (43). More research is needed for pilates and yoga before recommending as a part of a pain management plan for oncology patients (44).

\section{Other Interventions}

Therapeutic touch can be described as using the hands on or near the body to help a patient. The non-invasive technique is used by nurses to aid in energy transfer to promote healing. This should be considered in oncology patients as it can reduce pain, anxiety and nausea in cancer patients (45). Heat and ice/cryotherapy can be used to manage pain in cancer patients, but should be used with caution over insensate areas or over areas with active or unmanaged disease (36). Both aroma therapy and music therapy have been shown to reduce pain in peri-operative breast cancer patients however more research is needed to recommend in other populations (46).

\section{CONCLUSION}

Pain is a significant impairment that can limit a person's functional progress and cause psychological and physical distress while admitted to an inpatient rehabilitation 
facility. The rehabilitation team should consider a multimodal, multidisciplinary pain intervention strategy to help a patient achieve control. Recommendations for treatment should be made on a case-by-case basis with considerations for type of cancer, disease burden, location and overall prognosis.

\section{REFERENCES}

1. Cancer Stat Facts: Cancer of Any Site. Surveillance, Epidemiology, and End Results Program (SEER) Database. National Institutes of Health (NIH). (2021). Available online at: https://seer.cancer.gov/statfacts/html/all.html (accessed February 21, 2021).

2. Cancer Statistics. National Institutes of Health (NIH). (2021). Available online at: https://www.cancer.gov/about-cancer/understanding/statistics (accessed February 21, 2021)

3. Mix JM, Granger CV, LaMonte MJ, Niewczyk P, DiVita MA, Goldstein R, et al. Characteristics of cancer patients in inpatient rehabilitation facilities: a retrospective cohort study. Arch Phys Med and Rehab. (2017) 98:97180. doi: 10.1016/j.apmr.2016.12.023

4. Ture M, Angst F, Aeschlimann A, Renner C, Schnyder U, Zerkiebel, et al. Short-term effectiveness of inpatient cancer rehabilitation: A longitudinal controlled cohort study. J Cancer. (2017) 10:1717-25. doi: 10.7150/jca.19564

5. Ji RR, Berta T, Nedergaard M. Glia and pain: is chronic pain a gliopathy? Pain. (2013) 154(suppl. 1):S10-28. doi: 10.1016/j.pain.2013.06.022

6. Breivik H, Cherny N, Collett B, de Conno F, Filbet M, Foubert AJ, et al. Cancerrelated pain: a pan-European survey of prevalence, treatment and patient attitudes. Ann Oncol. (2009) 20:1420-33. doi: 10.1093/annonc/mdp001

7. Van den Beuken-van Everdingen MH, de Rijke JM, Kessels AG, Schouten HC, van Kleef M, Patijn J. Prevalence of pain in patients with cancer: a systematic review of the past 40 years. Ann Oncol. (2007) 18:143749. doi: 10.1093/annonc/mdm056

8. Nalamchu S. An overview of pain management: the clinical efficacy and value of treatment. Am J Manag Care. (2013) 19(Suppl. 14):s261-6.

9. National Comprehensive Cancer Network. Adult Cancer Pain: NCCN Clinical Practice Guidelines in Oncology, Version 2. (2016). https://www.nccn.org/ professionals/physician_gls/pdf/pain.pdf (accessed February 27, 2021).

10. Ventafridda V, Saita L, Rippamonti C, de Conno, F. WHO Guidelines for the use of analgesics in cancer pain. Int J Tissue React. (1985) 7:93-6.

11. Bennett M. What evidence do we have that the WHO analgesic ladder is effective in cancer pain? In: McQuay HJ, Kelso E, editors. Systematic Reviews in Pain Research: Methodology Refined. Seattle: IASP Press (2008).

12. Corli O, Floriani I, Roberto A, Montari M, Galli F, Greco MT, et al. Are strong opioids equally effective and safe in the treatment of chronic cancer pain? A multi-center randomized phase IV 'real life' trial on the variability of response to opioids. Ann Oncol. (2016) 27:1107-15. doi: 10.1093/annonc/mdw097

13. Bennett M, Paice J, Wallace M. Pain and opioids in cancer care: benefits, risks and alternatives. Am Soc Clin Oncol Educ Book. (2017) 37:70513. doi: 10.1200/EDBK_180469

14. Prescription Drug Coverage. Centers for Medicare and Medicaid Services. (2021). Available online at: https://www.cms.gov/Medicare/ Prescription-Drug-Coverage/PrescriptionDrugCovContra/Downloads/ Opioid-Morphine-EQ-Conversion-Factors-Aug-2017.pdf (accessed March 21, 2021).

15. De la Cruz M, Reddy A, Balankari V, Epner M, Hume-Frisbee S, Wu J, et al. The impact of an educational program on patient practices for safe use, storage and disposal of opioids at a comprehensive cancer center. Oncologist. (2017) 22:115-21. doi: 10.1634/theoncologist.2016-0266

16. Derry S, Moore RA. Single dose oral celecoxib for acute postoperative pain in adults. Cochrane Database Syst Rev. (2012) 3:CD004233. doi: 10.1002/14651858.CD004233.pub3

17. Nissen SE, Yeomans ND, Solomon DH, Luscher TF, Libby P, Husni $\mathrm{ME}$, et al. Cardiovascular safety of celecoxib, naproxen or ibuprofen for arthritis. N Engl J Med. (2016) 375:2519. doi: 10.1056/NEJMoa16 11593

\section{AUTHOR CONTRIBUTIONS}

TP primary author and literature review. FS and AK consultants for interventions and manuscript review and editing. All authors contributed to the article and approved the submitted version.

18. Derry C, Derry S, Moore RA, McQuay HJ. Single dose oral ibuprofen for acute postoperative pain in adults. Cochrane Database Syst Rev. (2009) 3:CD001548. doi: 10.1002/14651858.CD001548.pub2

19. Acetaminophen. PubChem. National Library of Medicine. Available online at: https://pubchem.ncbi.nlm.nih.gov/compound/Acetaminophen (accessed February 28, 2021).

20. Lopinzi CL, Laccheti C, Bleeker J, Cavaletti G, Chauhan C, Hertz DL, et al. Prevention and management of chemotherapy-induced peripheral neuropathy in survivors of adult cancers: ASCO guidelines update. J Clin Oncol. (2020) 38:3325-48. doi: 10.1200/JCO.20.01399

21. Anekar A, Cascella M. WHO Analgesic Ladder. Treasure Island, FL: Stat Pearls Publishing (2021).

22. Finnerup NB, Attal N, Haroutounian S, McNicol E, Baron R, Dworkin RH, et al. Pharmacotherapy for neuropathic pain in adults: a systematic review and meta-analysis. Lancet Neurol. (2015) 14:162-73. doi: 10.1016/S1474-4422(14)70251-0

23. Finnerup NB, Sindrup SH, Jensen TS. The evidence for pharmacological treatment of neuropathic pain. Pain. (2010) 150:573-81. doi: 10.1016/j.pain.2010.06.019

24. Pain Management. Boston Scientific. Available online at: https://www. bostonscientific.com/en-US/reimbursement/pain-management.html (accessed March 20, 2021).

25. Medicare Claims Processing Manual. Chapter 12. Centers for Medicare and Medicaid Services. Available online at: https://www.cms.gov/files/document/ medicare-claims-processing-manual-chapter- 12 (accessed March 20, 2021).

26. Zhang R, Lao L, Ren K, Berman BM. Mechanisms of acupunctureelectroacupuncture on persistent pain. Anesthesiology. (2014) 120:482503. doi: 10.1097/ALN.0000000000000101

27. Rittner HL, Brack A, Machelska H, Mousa SA, Bauer M, Schafer M, et al. Opioid peptide-expressing leukocytes: Identification, recruitment, and simultaneously increasing inhibition of inflammatory pain. Anesthesiology. (2001) 95:500-8. doi: 10.1097/00000542-200108000-00036

28. Shinoda M, Ogino A, Ozaki N, Urano H, Hironaka K, Yasui M, et al. Involvement of TRPV1 in nociceptive behavior in a rat model of cancer pain. J Pain. (2008) 9:687-99. doi: 10.1016/j.jpain.2008.02.007

29. He Y, Guo X, May BH, Zhang AL, Liu Y, Lu C, et al. Clinical evidence for association of acupuncture and acupressure with improved cancer pain: A systematic review and meta-analysis. JAMA Oncol. (2020) 6:2718. doi: 10.1001/jamaoncol.2019.5233

30. Cassileth BR, Deng G. Complementary and alternative therapies for cancer. Oncologist. (2004) 9:80-9. doi: 10.1634/theoncologist.9-1-80

31. Lee SH, Kim JY, Yeo S, Kim SH, Lim S. Meta-analysis of massage therapy on cancer pain. Integr Cancer Ther. (2015) 14:297-304. doi: 10.1177/1534735415572885

32. Sagar SM, Dryden T, Wong RK. Massage therapy for cancer patients: A reciprocal relationship between body and mind. Curr Oncol. (2007) 14:4556. doi: $10.3747 /$ co.2007.105

33. Jones I, Johnson MI. Transcutaneous electrical nerve stimulation. Contin Educ Anesthes Crit Care Pain. (2009) 9:130-5. doi: 10.1093/bjaceaccp/mkp021

34. Melzack R, Wall PD. Pain mechanisms: A new theory. Science. (1965) 150:971-99. doi: 10.1126/science.150.3699.971

35. Hurlow A, Bennett MI, Robb KA, Johnson MI, Simpson KH, Oxberry SG. Transcutaneous electrical nerve stimulation (TENS) for cancer pain in adults. Cochrane Database Syst Rev. (2012) 2012:CD006276. doi: 10.1002/14651858.CD006276.pub3

36. Maltser S, Cristian A, Silver JK, Morris GS, Stout NL. A focused review of safety considerations in cancer rehabilitation. PMR. (2017) 9:S41528. doi: 10.1016/j.pmrj.2017.08.403 
37. Yao C, Cheng Y, Zhu Q, Lv Z, Kong L, Fang M. Clinical evidence for the effects of manual therapy on cancer pain: A systematic review and meta-analysis. Evid Based Complement Alternat Med. (2021) 2021:6678184. doi: 10.1155/2021/6678184

38. Boyd C, Crawford C, Paat C, Price A, Xenakis L, Zhang W, et al. The impact of massage on function in pain populations: A systematic review and metaanalysis of randomized controlled trials: Part II, cancer pain populations. Pain Medicine. (2016) 17:1553-68. doi: 10.1093/pm/pnw100

39. Vas L, Phanse S, Pai R. A new perspective of neuromyopathy to explain intractable pancreatic cancer pains; Dry needling as an effective adjunct to neurolytic blocks. Indian J Palliat Care. (2016) 22:8593. doi: 10.4103/0973-1075.173957

40. Cillessen L, Johannsen M, Speckens AEM, Zachariae R. Mindfulness-based interventions for psychological and physical health outcomes in cancer patients and survivors: A systematic review and meta-analysis of randomized controlled trials. Psychooncology. (2019) 28:2257-69. doi: 10.1002/pon.5214

41. Husebø AML, Husebø TL. Quality of life and breast cancer: How can mind-body exercise therapies help? An overview study. Sports. (2017) 5:79. doi: $10.3390 /$ sports5040079

42. Pinto-Carral A, Molina AJ, de Pedro A, Ayan C. Pilates for women with breast cancer: A systematic review and meta-analysis. Complementary Ther Med. (2018) 41:130-40. doi: 10.1016/j.ctim.2018. 09.011

43. Danhauer SC, Addington EL, Cohen L, Sohl SJ, Van Puymbroeck $\mathrm{M}$, Albinati NK, et al. Yoga for symptom management in oncology: A review of the evidence base and future directions for research. Cancer. (2019) 125:1979989. doi: 10.1002/cncr. 31979
44. De Groef A, Penen F, Dams L, Van der Gucht E, Nijs J, Meeus M. Best-evidence rehabilitation for chronic pain part 2: Pain during and after cancer treatment. J Clin Med. (2019) 8:979. doi: 10.3390/jcm8070979

45. Tabatabaee A, Tafreshi MZ, Rassouli M, Aledavood SA, AlaviMajd H, Farahmand SK. Effect of therapeutic touch in patients with cancer: A literature review. Med Arch. (2016) 70:142-7. doi: 10.5455/medarh.2016.70.142-147

46. Xiao Y, Li L, Xie Y, Xu J, Liu Y. Effects of aroma therapy and music intervention on pain and anxious for breast cancer patients in the perioperative period. Zhong Nan Da Xue Bao Yi Xue Ban. (2018) 43:65661. doi: $10.11817 /$ j.issn.1672-7347.2018.06.013

Conflict of Interest: The authors declare that the research was conducted in the absence of any commercial or financial relationships that could be construed as a potential conflict of interest.

Publisher's Note: All claims expressed in this article are solely those of the authors and do not necessarily represent those of their affiliated organizations, or those of the publisher, the editors and the reviewers. Any product that may be evaluated in this article, or claim that may be made by its manufacturer, is not guaranteed or endorsed by the publisher.

Copyright $\odot 2021$ Pugh, Squarize and Kiser. This is an open-access article distributed under the terms of the Creative Commons Attribution License (CC BY). The use, distribution or reproduction in other forums is permitted, provided the original author(s) and the copyright owner(s) are credited and that the original publication in this journal is cited, in accordance with accepted academic practice. No use distribution or reproduction is permitted which does not comply with these terms. 